\title{
Factors Predictive of Protracted Course of Radiation Therapy in Patients Treated with Definitive Chemoradiation for Cervical Cancer
}

\author{
Mark Zaki $^{1}$, Michael Dominello ${ }^{2}$, Robert Morris ${ }^{3}$, Steven Miller ${ }^{4}$ \\ 1. Radiation Oncology, Detroit Medical Center 2. Department of Oncology, Division of Radiation \\ Oncology, Wayne State University School of Medicine 3. Gynecologic Oncology, Karmanos Cancer \\ Center, Wayne State University School of Medicine 4. Department of Oncology, Wayne State University \\ School of Medicine
}

$\square$ Corresponding author: Mark Zaki, mazaki@med.wayne.edu

Disclosures can be found in Additional Information at the end of the article

\section{Abstract}

\section{Background}

There is a benefit to completing definitive chemoradiotherapy (CRT) for cervical cancer within 56 days. However, many patients experience delays due to missed radiation treatments that prolong the overall course of therapy. In order to improve patient care, we performed a quality improvement project to determine factors predictive of protracted treatment and develop strategies to enable timely treatment completion.

\section{Methods}

Seventy-one patients treated for cervical cancer with CRT were identified. Medical records were reviewed to gather demographic, clinical, and treatment data. Prolonged treatment was defined as $>56$ days per the American Brachytherapy Society guidelines. The following variables were evaluated using paired t-tests and univariate logistic regression: demographics, Intensity Modulated Radiotherapy (IMRT) versus conventional radiation technique, use of a boost, time to stent placement, time to first brachytherapy (BT), and genitourinary (GU) or gastrointestinal (GI) toxicity.

\section{Results}

The median treatment length for all patients was 59 days. Factors associated with prolonged treatment were time to cervical stent placement $(\mathrm{p}=0.001)$, delay $\geqslant 2$ days between final external

Received 03/08/2016 Review began 03/09/2016 Review ended 03/21/2016 Published 04/04/2016

\section{C) Copyright 2016}

Zaki et al. This is an open access article distributed under the terms of the Creative Commons Attribution License CC-BY 3.0., which permits unrestricted use, distribution, and reproduction in any medium, provided the original author and source are credited. beam radiation therapy (EBRT) and initial BT ( $p=0.0195)$, any grade GU toxicity $(p=0.0007)$, or GI toxicity ( $p=0.0002)$, and the presence of a boost ( $p=0.0006)$. Age, stage, and IMRT versus conventional technique were not associated with protracted treatment.

\section{Conclusion}

In this series of patients, acute toxicity, increased time to cervical stent placement, and time to first BT treatment were associated with prolonged treatment time. The patients who completed treatment in $\leqslant 56$ days had a lower average time to cervical stent placement, 27 versus 31 days. Our results suggest that cervical stent placement during week four of treatment can enhance patient care and improve outcomes.

How to cite this article

Zaki M, Dominello M, Morris R, et al. (April 04, 2016) Factors Predictive of Protracted Course of Radiation Therapy in Patients Treated with Definitive Chemoradiation for Cervical Cancer. Cureus 8(4): e558. DOI 10.7759/cureus.558 
Categories: Obstetrics/Gynecology, Radiation Oncology, Quality Improvement

Keywords: cervical cancer

\section{Introduction}

Previous studies have demonstrated a benefit to completing definitive chemoradiotherapy (CRT) for cervical cancer within an eight-week period [1-8]. Furthermore, the American Brachytherapy Society (ABS) task group recommends finishing CRT within 56 days from the start of treatment [9]. Current Radiation Therapy Oncology Group (RTOG) and Gynecologic Oncology Group (GOG) cervical cancer protocols utilizing CRT recommend that treatment be completed within 56 days (eight weeks) [10-11] . Despite the well-established detriment of protracted treatment course, patients may, for various reasons, still experience delays that prolong the course of their treatment.

To determine potential causes of prolonged treatment, we investigated many possible factors. An important variable we examined was the time to cervical stent insertion. To facilitate insertion of a tandem, a cervical stent is typically inserted on the first day of, or prior to the start of, high-dose-rate brachytherapy (BT) treatment [12]. At many institutions including our own, a cervical stent is placed one or more days prior to the first BT treatment, though optimal time of placement is unknown. Placement early on, as the cervix is responding to therapy, may compromise the positioning of the stent, suture integrity, and dosimetry at the time of BT planning, whereas late placement may prolong overall treatment length. Our objective was to identify factors that may predict for prolonged treatment time, including time of stent placement, in order to implement strategies to enhance the quality of patient care.

\section{Materials And Methods}

After institutional review board (IRB) approval, seventy-one consecutive patients treated from 2008 to 2013 for cervical cancer with CRT followed by BT at our institution were identified. Medical records were reviewed to gather demographic, clinical, and treatment data. Informed consent was obtained from all participants. Prolonged treatment was defined as $>56$ days as per the American Brachytherapy Society (ABS) guidelines [13].

Outcomes were not analyzed in this report as our outcomes are expected to represent existing data. Therefore, we limited the scope of this project to analyze the demographic, clinical, and treatment-related factors associated with treatment prolongation in order to recommend quality improvement measures.

Total treatment time was calculated as the number of days from the date of the first radiation treatment to the last radiation treatment, including both external beam radiation therapy (EBRT) and BT. Treatment breaks were defined as any single break in radiation treatment $\geqslant 3$ days (excluding weekends or holidays) or multiple breaks during the course of radiation resulting in $\geqslant 5$ missed treatments. Toxicity was evaluated by assessments performed on weekly on-treatment visits.

Data was analyzed using SAS V. 9.2 (SAS Inc., Cary, NC). Treatment time was transformed into a dichotomous variable ( $\leqslant 56$ and $>56$ days). The variables related to increased treatment time were evaluated using paired t-tests and univariate logistic regression. Important univariate variables were then fit into a multivariable logistic model.

\section{Results}

In our series of patients, the median age was 50. Thirty-nine percent of patients had FIGO stage 


\section{Cureus}

I disease, 39\% had stage II, 16\% had stage III, and 6\% had stage IV. (FIGO is International Federation of Gynecology and Obstetrics). Median EBRT dose was $45 \mathrm{~Gy}$ in 25 fractions of 1.8 Gy to the pelvis \pm para-aortic lymph nodes, with a 5.4 Gy sidewall or parametrial boost. The median BT dose was 27.5 Gy in 5 fractions. Sixty-six percent were treated with 3-D conformal radiation and 34\% using IMRT. Sixty-eight women had high-dose-rate BT with a ring and tandem applicator, whereas three underwent an interstitial implant. Table 1 highlights the characteristics of patients in our cohort.

\section{Patient Characteristics}

Median age

Stage

I

II

III

$11(16 \%)$

IV

EBRT dose (median) 45 Gy

Boost dose (median)

HDR dose (median)

4-field technique

IMRT

Ring and tandem

Interstitial implant

Length of treatment (median)

First treatment to cervical stent placement (median)

\section{TABLE 1: Patient characteristics}

EBRT- external beam radiation therapy. HDR - high-dose rate brachytherapy. IMRT - intensity modulated radiation therapy.

For the 68 patients requiring a cervical stent prior to application of the ring and tandem, the median time from start of EBRT to the cervical stent placement and first BT was 29 and 38 days, respectively. The median treatment length for all patients was 59 days. Fifty-one percent of patients had one or more breaks in treatment and 59\% of those breaks were either due to social issues or non-compliance.

In addition to the time of stent placement, the following variables were evaluated: age, race, 
distance to cancer center, use of IMRT versus conventional radiation technique, use of a boost, time to first BT, and GU or GI toxicity. Factors associated with prolonged treatment time were time to cervical stent placement $(\mathrm{p}=0.001)$, delay $\geqslant 2$ days between last fraction of EBRT and delivery of first BT ( $p=0.0195)$, any grade GU toxicity ( $p=0.0007)$, or GI toxicity ( $p=0.0002)$, and the presence of a boost ( $\mathrm{p}=0.0006)$. Age, race, stage, distance to cancer center, and radiation technique (IMRT v. 3-D) were not significantly associated with prolonged treatment time. Figure 1 shows the relationship between the timing of cervical stent placement and overall treatment time.

When excluding patients with any radiation treatment breaks, the following factors remained associated with prolonged treatment: time to cervical stent placement, with a mean of 31 days versus 27 days ( $\mathrm{p}=0.05$ ), and time to first BT treatment, with a mean of 47 days versus 34 days in patients completing treatment in $>56$ and $\leqslant 56$ days respectively $(\mathrm{p}=0.01)$.

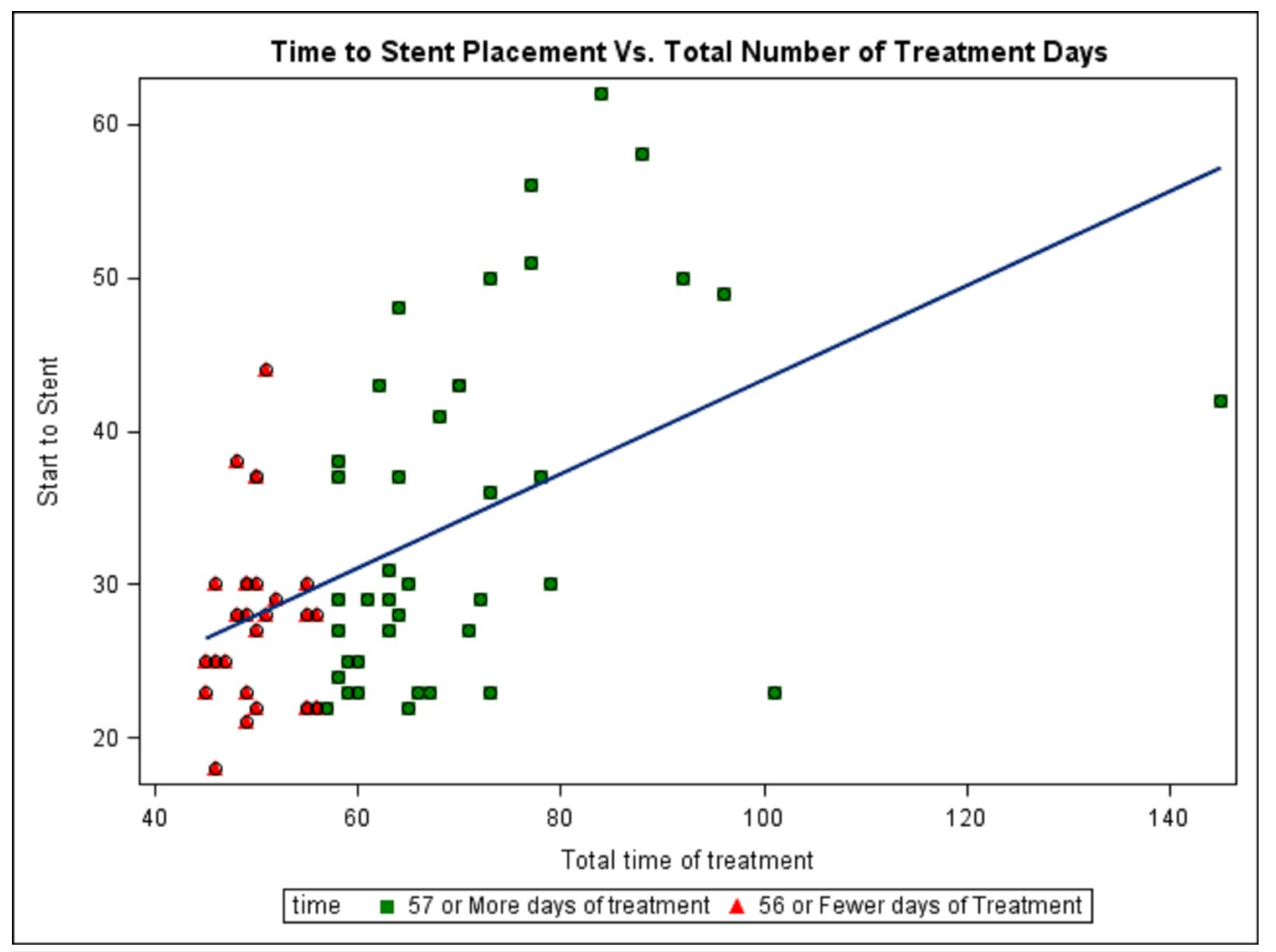

FIGURE 1: Graphical representation of time from first external beam radiation treatment to cervical stent placement versus total time of treatment, including a regression plot.

\section{Discussion}

Overall treatment length of $>56$ days is detrimental for patients receiving definitive CRT therapy for cervical cancer [1-8], yet many patients do not complete treatment in this acceptable time period. Prolonged treatment duration has been shown to decrease pelvic tumor control by an estimated $0.3-1.6 \%$ per day of prolongation $[1,2,4,7-8]$. Tumor regrowth by repopulation of surviving tumor cells during fractionated radiotherapy is the reason why local control rate decreases with time [14]. This radiobiological mechanism is critical in cervical cancer which demonstrates accelerated repopulation with a short onset time [15], magnifying the importance of reducing treatment time in this disease. 
Treatment breaks, whatever their cause, are a significant source of protracted treatment time. Every effort should be made to limit preventable breaks in therapy. This involves counseling patients on the importance of maintaining compliance to the established treatment schedule. Selected patients may also benefit from a social work evaluation to optimize external factors and social issues, as well as a psychiatric evaluation for management of co-morbid psychiatric illnesses such as depression or anxiety disorders [16-17]. This evidently plays a central role in compliance to treatment. In our study cohort, $51 \%$ of patients experienced one or more treatment breaks and $59 \%$ of breaks were due to social issues or non-adherence.

Additionally, treatment breaks, whether physician-approved or not, can also be caused by treatment-related toxicity [18-19]. Patients experience variable levels of toxicity during CRT. In our cohort, any grade GU or GI toxicity was strongly correlated with prolonged treatment length ( $p=0.0007$ and $p=0.0002$, respectively). It is crucial to promptly recognize and appropriately manage these side effects during the course of treatment to enable a patient to complete treatment in an acceptable time frame. Most common side effects include urinary and gastrointestinal irritation. Noninfectious dysuria can be managed with local analgesics such as phenazopyridine; nausea and vomiting is managed effectively with antiemetics such as odansetron or prochlorperazine; diarrhea is generally well-controlled with antidiarrheal medications such as loperamide or diphenoxylate/atropine [20].

The timing of BT must be carefully planned, using clinical and radiographic assessments. Early BT may not allow enough time for initial EBRT and chemotherapy to reduce the tumor size enough, compromising dosimetry at the time of BT; whereas BT started late in the course of BT may prolong the overall treatment time which may be detrimental to clinical outcomes. It has been shown that in addition to clinical examination, magnetic resonance imaging (MRI) is a valuable diagnostic tool that can often detect a significant amount of tumor reduction prior to the initial BT treatment and at each subsequent BT application [21-22]. The ABS task group recommends that highdose rate (HDR) BT commence after $39.6 \mathrm{~Gy}$ or $45 \mathrm{~Gy}$ with up to two BT treatments given per week during the conclusion of EBRT and that BT begins no earlier than approximately $20 \mathrm{~Gy}$ [9]. It should also be noted that the European study on MRI-guided brachytherapy in locally advanced cervical cancer (EMBRACE Study), endorsed by the Groupe Européen de Curiethérapie (GEC) and the European SocieTy for Radiotherapy \& Oncology (ESTRO) (GEC-ESTRO) requires that all treatment be completed within 50 days [23]. Consistent with the ABS and GEC-ESTRO recommendations [9, 24], our study shows that cervical stent placement by the fourth week of EBRT would largely permit HDR BT to begin around $39.6 \mathrm{~Gy}$, and is associated with satisfactory treatment duration.

A conceivable drawback of brachytherapy is that it is invasive, resource-intensive, and involves sedation or anesthesia. The recovery time from a brachytherapy procedure could also potentially contribute to a delay in overall treatment time. Completing all radiation treatments via EBRT is a promising, non-invasive way to limit treatment breaks, particularly in patients with poor performance status who are not suitable candidates for BT. Some investigators have published early experience with stereotactic body radiation therapy (SBRT) as a BT substitute in poor BT candidates. In retrospective series, SBRT provided adequate target coverage and satisfactory doses to organs at risk, with good toxicity profiles and clinical results on early follow-up [25-27]. Yet prospective data regarding SBRT boost are lacking and therefore it is not recommended as first-line treatment for patients who are BT candidates, outside of a clinical trial [28].

It is intuitive that reducing treatment breaks is fundamental, yet our quality improvement study importantly identifies time to cervical stent placement as an additional significant factor for achieving a satisfactory overall treatment time. When assessing patients in our cohort who completed treatment without a break in radiation, time to cervical stent placement was still a significant factor that predicted for completing treatment in $\leqslant 56$ days. Scheduling cervical stent 
insertion during the fourth week of treatment is easily applicable and has a high likelihood of success at many institutions. We plan on implementing this intervention at our own institution. This key measure has the potential to significantly improve outcomes.

\section{Conclusions}

In this series of patients, acute toxicity, increased time to cervical stent placement, and time to first BT treatment were associated with prolonged treatment time. Preventing unnecessary treatment breaks and treating acute toxicity effectively remains essential. Additionally, our results suggest that cervical stent placement during the fourth week of treatment may be effective in enhancing patient care and improving outcomes.

\section{Additional Information \\ Disclosures}

Human subjects: Consent was obtained by all participants in this study. Animal subjects: All authors have confirmed that this study did not involve animal subjects or tissue. Conflicts of interest: In compliance with the ICMJE uniform disclosure form, all authors declare the following: Payment/services info: All authors have declared that no financial support was received from any organization for the submitted work. Financial relationships: All authors have declared that they have no financial relationships at present or within the previous three years with any organizations that might have an interest in the submitted work. Other relationships: All authors have declared that there are no other relationships or activities that could appear to have influenced the submitted work.

\section{References}

1. Chen SW, Liang JA, Yang SN, Ko HL, Lin FJ: The adverse effect of treatment prolongation in cervical cancer by high-dose-rate intracavitary brachytherapy. Radiother Oncol. 2003, 67:6976. 10.1016/S0167-8140(02)00439-5

2. Fyles A, Keane TJ, Barton M, Simm J: The effect of treatment duration in the local control of cervix cancer. Radiother Oncol. 1992, 25:273-279. 10.1016/0167-8140(92)90247-R

3. Monk BJ, Tian C, Rose PG, Lanciano R: Which clinical/pathologic factors matter in the era of chemoradiation as treatment for locally advanced cervical carcinoma? Analysis of two gynecologic oncology group (GOG) trials. Gynecol Oncol. 2007, 105:427-433. 10.1016/j.ygyno.2006.12.027

4. Perez CA, Grigsby PW, Castro-Vita H, Lockett MA: Carcinoma of the uterine cervix. I. Impact of prolongation of overall treatment time and timing of brachytherapy on outcome of radiation therapy. Int J Radiat Oncol Biol Phys. 1995, 32:1275-1288. 10.1016/03603016(95)00220-S

5. Petereit DG, Sarkaria JN, Chappell R, Fowler JF, Hartmann TJ, Kinsella TJ, Stitt JA, Thomadsen $\mathrm{BR}$, Buchler DA: The adverse effect of treatment prolongation in cervical carcinoma . Int J Radiat Oncol Biol Phys. 1995, 32:1301-1307. 10.1016/0360-3016(94)00635-X

6. Song S, Rudra S, Hasselle MD, Dorn PL, Mell LK, Mundt AJ, Yamada SD, Lee NK, Hasan Y: The effect of treatment time in locally advanced cervical cancer in the era of concurrent chemoradiotherapy. Cancer. 2013, 119:325-331. 10.1002/cncr.27652

7. Girinsky T, Rey A, Roche B, Haie C, Gerbaulet A, Randrianarivello H, Chassagne D: Overall treatment time in advanced cervical carcinomas: a critical parameter in treatment outcome. Int J Radiat Oncol Biol Phys. 1993, 27:1051-1056. 10.1016/0360-3016(93)90522-W

8. Lanciano RM, Pajak TF, Martz K, Hanks GE: The influence of treatment time on outcome for squamous cell cancer of the uterine cervix treated with radiation: a patterns-of-care study. Int J Radiat Oncol Biol Phys. 1993, 25:391-397. 10.1016/0360-3016(93)90058-4

9. Viswanathan A, Thomadsen B: American Brachytherapy Society Cervical Cancer Brachytherapy Task Group . Accessed: 22 May 2014: http://www.americanbrachytherapy.org/guidelines/cervical_cancer_taskgroup.pdf.

10. Schefter TE, Winter K, Kwon JS, Stuhr K, Balaraj K, Yaremko BP, Small W Jr, Gaffney DK: A 
phase II study of bevacizumab in combination with definitive radiotherapy and cisplatin chemotherapy in untreated patients with locally advanced cervical carcinoma: preliminary results of RTOG 0417. Int J Radiat Oncol Biol Phys. 2012, 83:1179-1184. Accessed: 22 May 2014: http://www.ncbi.nlm.nih.gov/pubmed/22342094. 10.1016/j.ijrobp.2011.10.060

11. DiSilvestro PA, Ali S, Craighead PS, Lucci JA, Lee YC, Cohn DE, Spirtos NM, Tewari KS, Muller C, Gajewski WH, Steinhoff MM, Monk BJ: Phase III randomized trial of weekly cisplatin and irradiation versus cisplatin and tirapazamine and irradiation in stages IB2, IIA, IIB, IIIB, and IVA cervical carcinoma limited to the pelvis: a Gynecologic Oncology Group study. J Clin Oncol. 2014, 32:458-464. Accessed: 22 May 2014: http://www.ncbi.nlm.nih.gov/pubmed/24395863. 10.1200/JCO.2013.51.4265

12. Smit BJ, du Toit JP, Groenewald WA: An indwelling intrauterine tube to facilitate intracavitary radiotherapy of carcinoma of the cervix. Br J Radiol. 1989, 62:68-69. 10.1259/0007-1285-62733-68

13. Nag S, Erickson B, Thomadsen B, Orton C, Demanes JD, Petereit D: The American Brachytherapy Society recommendations for high-dose-rate brachytherapy for carcinoma of the cervix. Int J Radiat Oncol Biol Phys. 2000, 48:201-211. 10.1016/S0360-3016(00)00497-1

14. Yang J, Yue JB, Liu J, Yu JM: Repopulation of tumor cells during fractionated radiotherapy and detection methods (Review). Oncol Lett. 2014, 7:1755-1760. 10.3892/ol.2014.1990

15. Huang Z, Mayr NA, Gao M, Lo SS, Wang JZ, Jia G, Yuh WT: Onset time of tumor repopulation for cervical cancer: first evidence from clinical data. Int J Radiat Oncol Biol Phys. 2012, 84:478484. 10.1016/j.ijrobp.2011.12.037

16. Johnson RL, Gold MA, Wyche KF: Distress in women with gynecologic cancer . Psychooncology. 2010, 19:665-668. 10.1002/pon.1589

17. Pasquini M, Biondi M: Depression in cancer patients: a critical review . Clin Pract Epidemiol Ment Health. 2007, 3:2. 10.1186/1745-0179-3-2

18. Runowicz CD, Wadler S, Rodriguez-Rodriguez L, Litwin P, Shaves M, O'Hanlan KA, Goldberg GL, Tomaino CT, Byrnes R: Concomitant cisplatin and radiotherapy in locally advanced cervical carcinoma. Gynecol Oncol. 1989, 34:395-401. 10.1016/0090-8258(89)90180-7

19. Twiggs LB, Potish RA, McIntyre S, Adcock LL, Savage JE, Prem KA: Concurrent weekly cisplatinum and radiotherapy in advanced cervical cancer: a preliminary dose escalating toxicity study. Gynecol Oncol. 1986, 24:143-148. 10.1016/0090-8258(86)90020-X

20. Berkey FJ: Managing the adverse effects of radiation therapy . Am Fam Physician. 2010, 82:381-388.

21. Dimopoulos JC, Petrow P, Tanderup K, Petric P, Berger D, Kirisits C, Pedersen EM, van Limbergen E, Haie-Meder C, Potter R: Recommendations from Gynaecological (GYN) GECESTRO Working Group (IV): basic principles and parameters for MR imaging within the frame of image based adaptive cervix cancer brachytherapy. Radiother Oncol. 2012, 103:113-122. 10.1016/j.radonc.2011.12.024

22. Dimopoulos JC, Schirl G, Baldinger A, Helbich TH, Potter R: MRI assessment of cervical cancer for adaptive radiotherapy. Strahlenther Onkol. 2009, 185:282-287. 10.1007/s00066-009-19187

23. A European study on MRI-guided brachytherapy in locally advanced cervical cancer . Accessed: 14 March 2016: http://https://www.embracestudy.dk/.

24. Haie-Meder C, Potter R, Van Limbergen E, Briot E, De Brabandere M, Dimopoulos J, Dumas I, Hellebust TP, Kirisits C, Lang S, Muschitz S, Nevinson J, Nulens A, Petrow P, WachterGerstner N, Gynaecological GECEWG: Recommendations from Gynaecological (GYN) GEC-

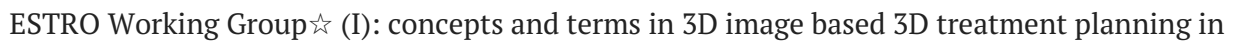
cervix cancer brachytherapy with emphasis on MRI assessment of GTV and CTV. Radiother Oncol. 2005, 74:235-245. 10.1016/j.radonc.2004.12.015

25. Marnitz S, Kohler C, Budach V, Neumann O, Kluge A, Wlodarczyk W, Jahn U, Gebauer B, Kufeld M: Brachytherapy-emulating robotic radiosurgery in patients with cervical carcinoma . Radiat Oncol. 2013, 8:109. 10.1186/1748-717X-8-109

26. Haas JA, Witten MR, Clancey O, Episcopia K, Accordino D, Chalas E: CyberKnife boost for patients with cervical cancer unable to undergo brachytherapy. Front Oncol. 2012, 2:25. 10.3389/fonc.2012.00025

27. Kubicek GJ, Xue J, Xu Q, Asbell SO, Hughes L, Kramer N, Youssef A, Chen Y, Aikens J, Saul H, Pahlajani N, LaCouture T: Stereotactic body radiotherapy as an alternative to brachytherapy in gynecologic cancer. Biomed Res Int. 2013, 2013:898953. 10.1155/2013/898953 


\section{Cureus}

28. Al Feghali KA, Elshaikh MA: Why brachytherapy boost is the treatment of choice for most women with locally advanced cervical carcinoma?. Brachytherapy. 2016, 15:191-199.

10.1016/j.brachy.2015.12.003 